\title{
ATOMIC LAYER DEPOSITED ALUMINA FOR USE AS AN ETCH BARRIER AGAINST XENON DIFLUORIDE ETCHING \\ Gabriel L. Smith ${ }^{1 *}$, Ronald G. Polcawich ${ }^{1 * *}$, Jeffrey S. Pulskamp ${ }^{l}$, Todd Waggoner ${ }^{2}$, and John F. Conley, Jr. ${ }^{2}$ \\ ${ }^{1}$ US Army Research Laboratory, Adelphi, MD, USA \\ ${ }^{2}$ Oregon State University, Electrical Engineering and Computer Science, Corvallis,OR, USA
}

\begin{abstract}
Xenon difluoride $\left(\mathrm{XeF}_{2}\right)$ isotropic etching is widely used to release silicon MEMS parts. To realize more complex devices using silicon-on-insulator (SOI) wafers requires the use of a conformal coating of patterned photoresist to selectively protect the device layer Si during the isotropic etch release of the handle wafer. As an alternative to the photoresist protective layer, an ion-mill patterned atomic layer deposited (ALD) alumina $\left(\mathrm{Al}_{2} \mathrm{O}_{3}\right)$ layer was investigated to dramatically improve device yields, particularly in avoiding edge defects and corner pinholes resulting in unintended etching of the silicon. Promising results have been obtained using $25 \mathrm{~nm}-200 \mathrm{~nm}$ layers of alumina on deeply etched silicon features. This will enable the fabrication of new MEMS silicon devices with reduced feature size for improved performance.
\end{abstract}

\section{INTRODUCTION}

Isotropic silicon etching with sulfur hexafluoride $\left(\mathrm{SF}_{6}\right)$ and xenon difluoride $\left(\mathrm{XeF}_{2}\right)$ has been used for more than a decade to release MEMS parts $[1,2,3]$. The process requires the use of a conformal coating to selectively protect critical silicon features from etch gases. One limitation with using $\mathrm{XeF}_{2}$ has been the difficulty in fabricating parts on relatively thick SOI wafers, especially as the Si device layer thickness increases into the 10's of microns. Previous work on using a photoresist encapsulation layer to protect the device layer has proven successful for both piezoelectric MEMS (PiezoMEMS) resonators [4] and PiezoMEMS lateral actuators [5] (see Figure 1). However, the process has been limited to device layers less than $20 \mu \mathrm{m}$ thick for a resist thickness of $10 \mu \mathrm{m}$. Even at these thicknesses, slight imperfections in resist coating lead to unintended etching of the $\mathrm{Si}$ device layer and compromised device yield (see Figures $2 \& 3$ ).

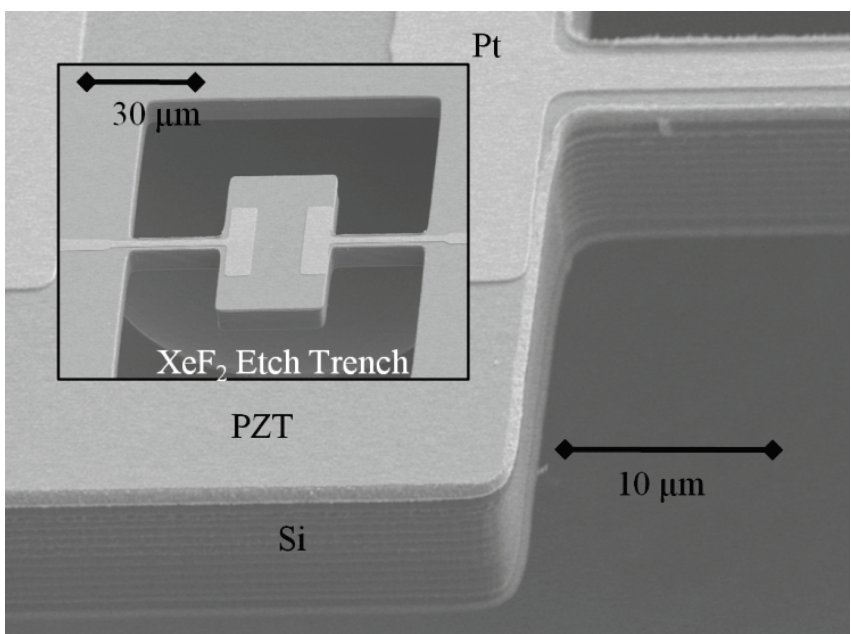

Figure 1: SEM micrographs of piezoelectric MEMS on SOI resonators, a) full device and b) resonator sidewall utilizing a successful photoresist encasement layer to protect the device silicon layer during a $\mathrm{XeF}_{2}$ etch release of the handle wafer silicon.

In order to provide improvements to the existing PiezoMEMS on SOI device release process, an alternative approach has been investigated using atomic layer deposition (ALD) films to provide etch protection. ALD films are appealing because they provide highly conformal protective coatings [6], are thin enough so as to

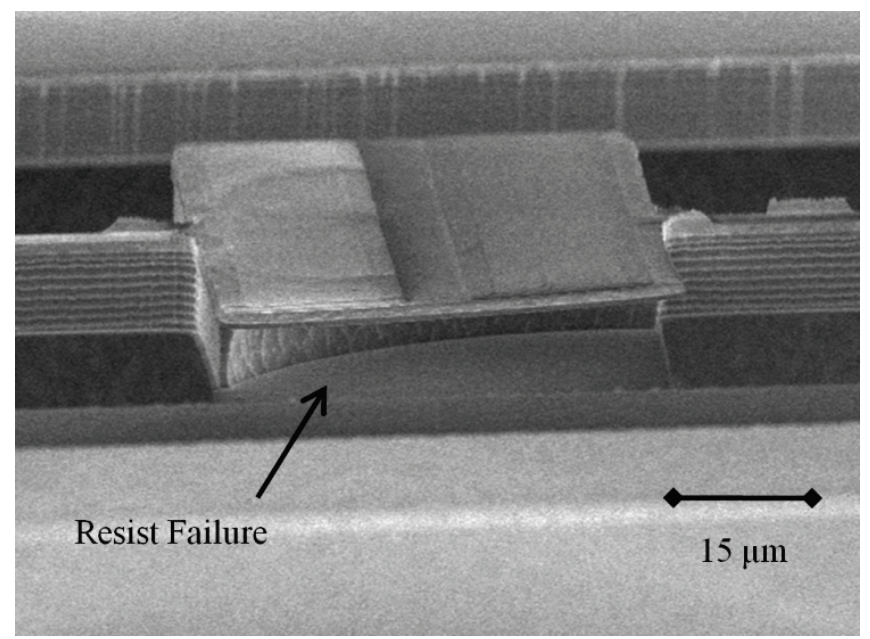

Figure 2: SEM highlighting unintended $\mathrm{XeF}_{2}$ etching of the Si device layer due to a resist encapsulation layer failure in a piezoelectric MEMS resonator.

not drastically alter mechanical properties such as stiffness (actuators) or loss (resonators), and could improve device perfomance by relaxing fabrication design rules. Additionally, photolithographically patterned ion milling of the ALD materials was investigated to demonstrate compatibility of the ALD coatings with photolithography and etch processes.

\section{RESULTS}

Four sets of experiments were conducted. The first experiment assessed the $\mathrm{XeF}_{2}$ etch selectivity of silicon to both ALD $\mathrm{Al}_{2} \mathrm{O}_{3}$ and $\mathrm{ALD} \mathrm{TiO}_{2}$. The second experiment determined the required ALD thickness for adequate protection using the superior of the two materials. The third experiment was done to determine if the results of ALD films deposited at Oregon State (Picosun Sunale tool) could be repeated on a Cambridge Nanotech ALD tool located at US Army Research Laboratory (ARL). The final experiment was to demonstrate released silicon features in a SOI process utilizing photolithographically defined conformal ALD films as device passivation followed by $\mathrm{XeF}_{2}$ etching of the unpassivated handle wafer silicon.

The following experiments were performed to identify suitable ALD materials and thicknesses that would adequately protect areas of exposed silicon. First, a $15 \mu \mathrm{m}$ deep reactive ion 


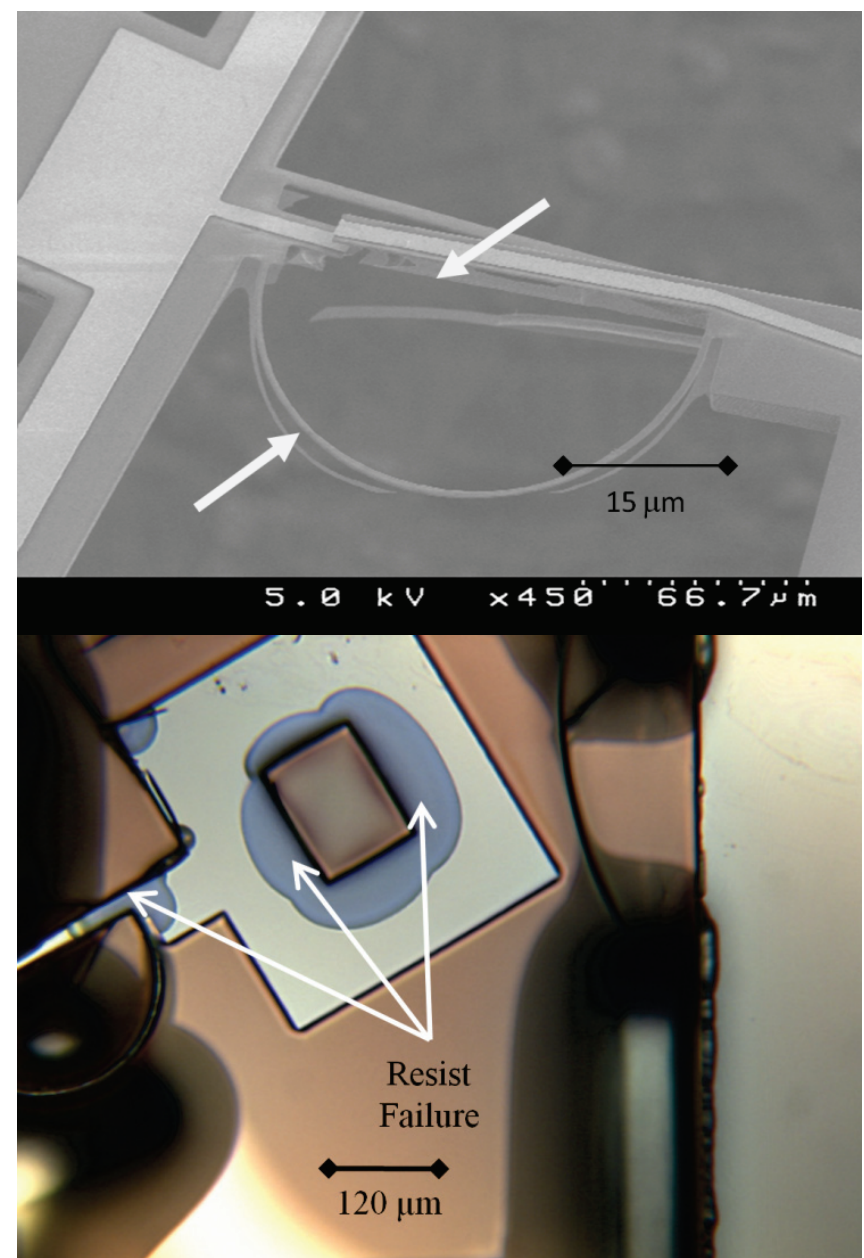

Figure 3: a) SEM and b) Optical micrograph highlighting resist encapsulation layer failures resulting in unintended $\mathrm{XeF}_{2}$ etching of the Si device layer in a PZT lateral actuator. Arrows are used to highlight cracks in the photoresist, failed flexures, and etched corners.

etched (DRIE) pattern was formed into a silicon substrate. Subsequently, the wafer was cut into sections with each section receiving a different ALD coating. ALD coatings of $\mathrm{Al}_{2} \mathrm{O}_{3}$ and $\mathrm{TiO}_{2}$ were deposited in a continuous flow Picosun Sunale R-150 reactor. $\mathrm{Al}_{2} \mathrm{O}_{3}$ films were deposited at $300^{\circ} \mathrm{C}$ using alternating pulses of trimethyl aluminum (TMA) and deionized water separated by $\mathrm{N}_{2}$ purges. The $\mathrm{Al}_{2} \mathrm{O}_{3}$ deposition rate was 0.089 $\mathrm{nm} /$ cycle or $\sim 1.3 \mathrm{~nm} / \mathrm{min}$. $\mathrm{TiO}_{2}$ films were deposited at $250^{\circ} \mathrm{C}$ using alternating pulses of titanium tetraisopropoxide (TTIP) and deionized water separated by $\mathrm{N}_{2}$ purges. The $\mathrm{TiO}_{2}$ deposition rate was $0.03 \mathrm{~nm} /$ cycle or $0.14 \mathrm{~nm} /$ min. Following the deposition (see Figure 4 for SEM cross-section), the wafer sections were exposed to 50 etch cycles in a Xactix Xetch system using an etch configuration of $20 \mathrm{~s}$ per cycle, $2 \mathrm{~T} \mathrm{XeF}_{2}$, and $20 \mathrm{~T} \mathrm{~N}_{2}$.

The initial experiments focused on thicker coatings of $200 \mathrm{~nm}$ for each material. As shown in Figure 5 and 6, only the alumina coating successfully protected the underlying $\mathrm{Si}$ from the $\mathrm{XeF}_{2}$ etch. The $\mathrm{TiO}_{2}$ layer etched and became porous enough to allow the free fluorine radicals to attack the underlying $\mathrm{Si}$. In order to determine the minimum required thickness, alumina coatings of $10,25,50$ and $100 \mathrm{~nm}$ were coated and subjected to the same 50 cycles of $\mathrm{XeF}_{2}$. Plan view optical micrographs taken after the etch highlight small areas of etched $\mathrm{Si}$ in both the $10 \mathrm{~nm}$ and $25 \mathrm{~nm}$

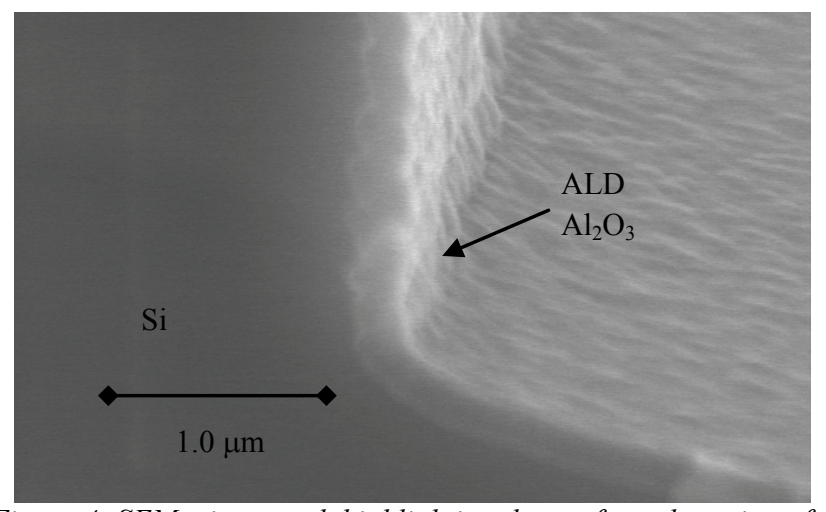

Figure 4: SEM micrograph highlighting the conformal coating of a $200 \mathrm{~nm} \mathrm{ALD} \mathrm{Al}_{2} \mathrm{O}_{3}$ near the base of a cleaved cross-section of a 15 $\mu \mathrm{m}$ DRIE trench.

samples (see Figure 7-8). These etch areas appear to be indicative of small defects in the coating either related to inadequate coverage or pinholes from contaminates. In contrast, both the $50 \mathrm{~nm}$ and 100 $\mathrm{nm}$ samples exhibited no evidence of silicon etching (see Figure 910). The results from this initial experiment indicate the minimum thickness for adequate protection of device $\mathrm{Si}$ features using ALD alumina may be in the range of $25-50 \mathrm{~nm}$ using the nonoptimized coating process mentioned early.

Subsequent testing was performed to verify the results of the tests on the Oregon State Picosun Sunale ALD films using a Cambridge Nanotech Fiji F200 ALD reactor installed at ARL. Another process difference is the reaction temperature was reduced from $300^{\circ} \mathrm{C}$ to $200^{\circ} \mathrm{C}$ improving the thermal process compatibility with ARL's PiezoMEMS fabrication process. The Fiji alternates $60 \mathrm{~ms}$ TMA and deionized water separated with 16 second purge cycles. Deposition times were on the order of $0.1 \mathrm{~nm} /$ cycle or 0.2 $\mathrm{nm} / \mathrm{min}$. ALD films with thicknesses of 10,25 and $50 \mathrm{~nm}$ were deposited. Similar excellent results were obtained with these films as with those deposited by the Oregon State reactor. Additional $\mathrm{XeF}_{2}$ etch cycles were performed (up to 500 cycles) to further examine of the survivability of the $\mathrm{Al}_{2} \mathrm{O}_{3}$ films. After 500 etch cycles, the films continued to show no signs of decreased etch protection.

The final test for this study involved a mask set that created patterned features in the conformal ALD film using a process flow compatible with the back end of the PiezoMEMS resonator fabrication process (see Table 1). The wafers were first deposited with a $\mathrm{SiO}_{2}$ coating followed by a $\mathrm{Ti} / \mathrm{Au}$ coating for bond pads. Next, the 10 micron device silicon, buried oxide, and a small portion of the handle wafer were etched by a series of DRIE, RIE, and DRIE etches.

Next, a $50 \mathrm{~nm}$ ALD alumina coating was deposited on the wafer. The ALD features were patterned with AZ 9245 photo resist and argon ion-milled to expose regions of the silicon handle wafer to the $\mathrm{XeF}_{2}$ gas. After ion milling the devices were stripped and subsequently etched in $\mathrm{XeF}_{2}$. Figures 11 and 12 show the results of a partially undercut device. The silicon disk is protected from the $\mathrm{XeF}_{2}$ gas by the ALD film on the top and sides and the buried $\mathrm{SiO}_{2}$ layer on the bottom. Examination of a majority of devices from this wafer has failed to identify any significant failures in the ALD protective coating on the sidewalls of the device layer silicon. This process should reliably eliminate the undesired etch problems illustrated in Figures 2 and 3 where broken structures and random etch holes in the device silicon caused failure. 


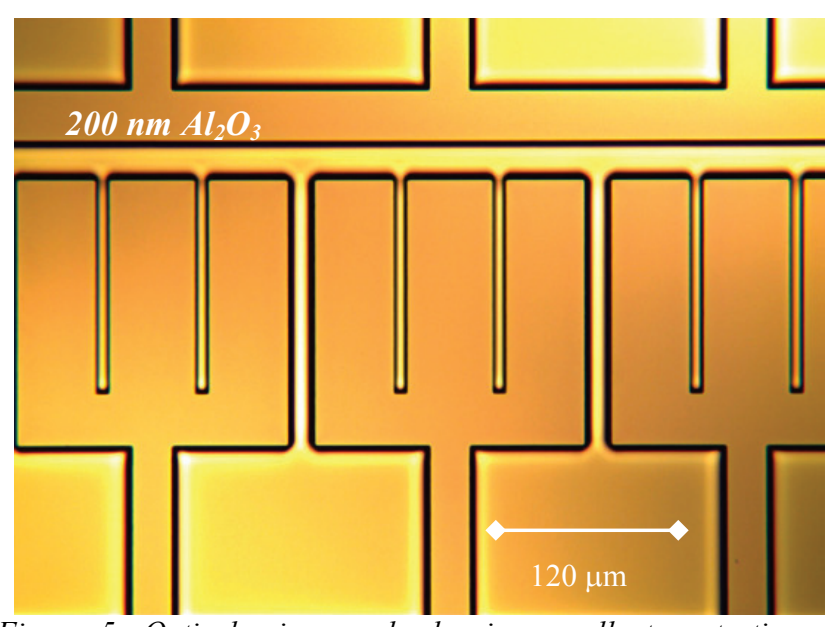

Figure 5: Optical micrograph showing excellent protection of silicon from $\mathrm{XeF}_{2}$ with a $200 \mathrm{~nm} \mathrm{ALD} \mathrm{Al}_{2} \mathrm{O}_{3}$ layer.

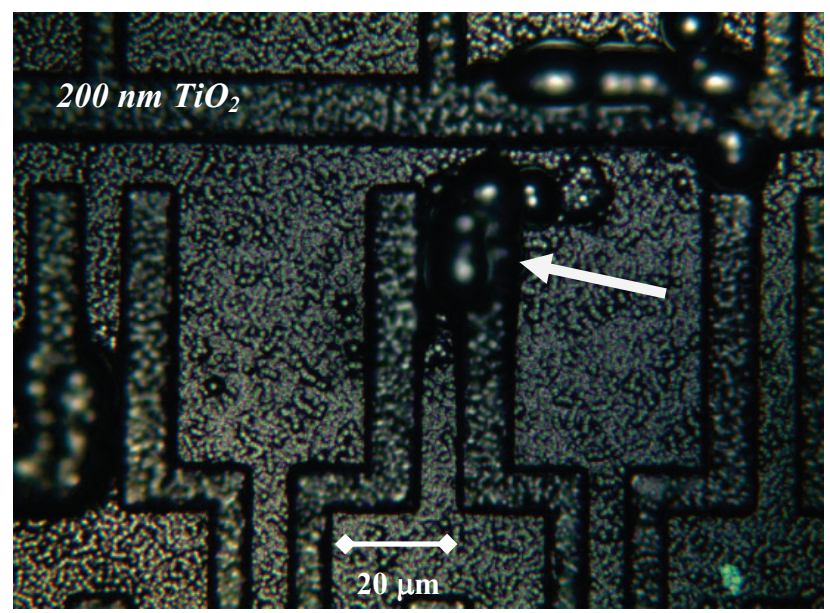

Figure 6: Optical micrograph showing failed $\mathrm{XeF}_{2}$ protection of silicon structures with $200 \mathrm{~nm}$ of $\mathrm{TiO}_{2}$.

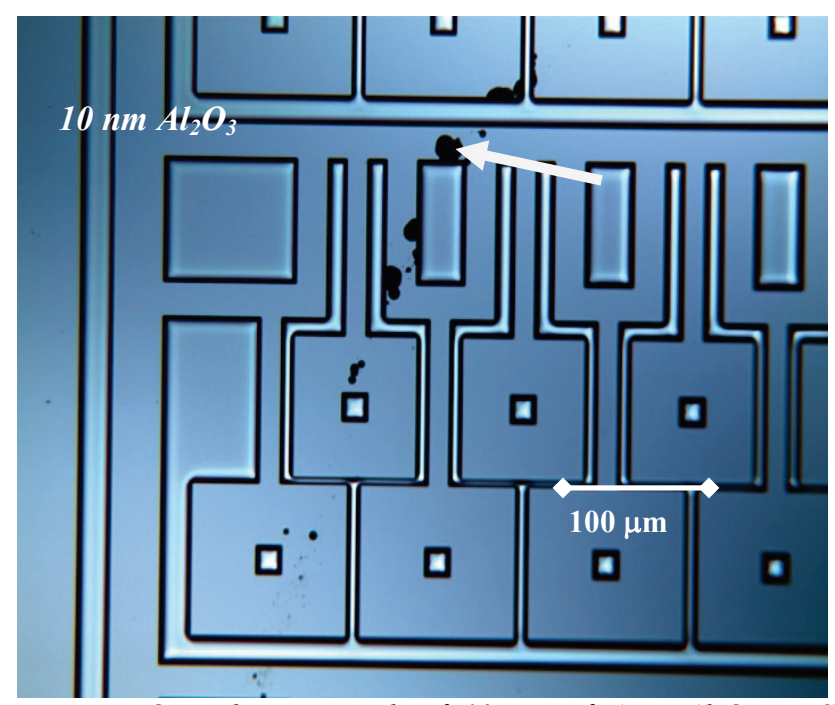

Figure 7: Optical micrograph of $10 \mathrm{~nm}$ of $\mathrm{ALD} \mathrm{Al}_{2} \mathrm{O}_{3}$ on $\mathrm{Si}$ features after $50 \mathrm{XeF}_{2}$ etch cycles showing unintended etching. The pattern indicates a contaminate on the wafer caused the failure.

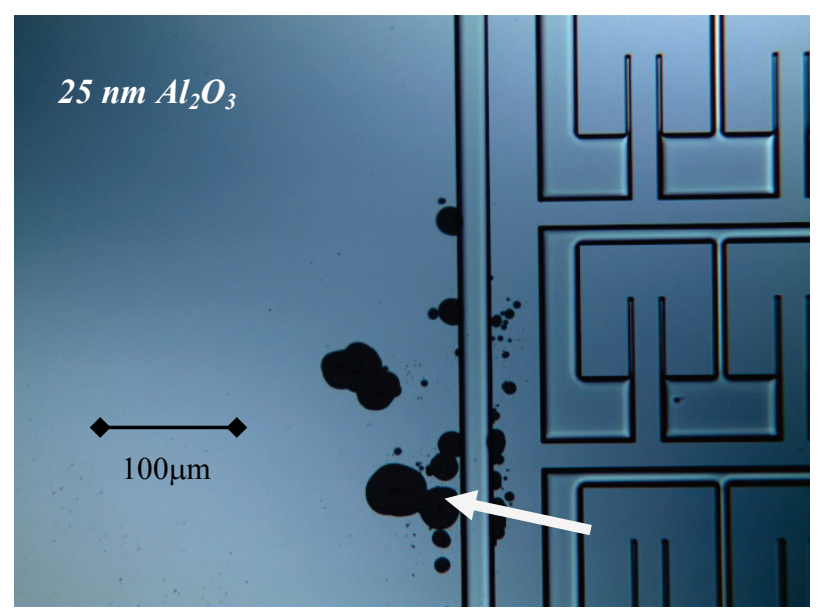

Figure 8: Optical micrograph of $25 \mathrm{~nm}$ of $\mathrm{ALD} \mathrm{Al}_{2} \mathrm{O}_{3}$ on Si after $50 \mathrm{XeF}_{2}$ etch cycles showing unintended etching.

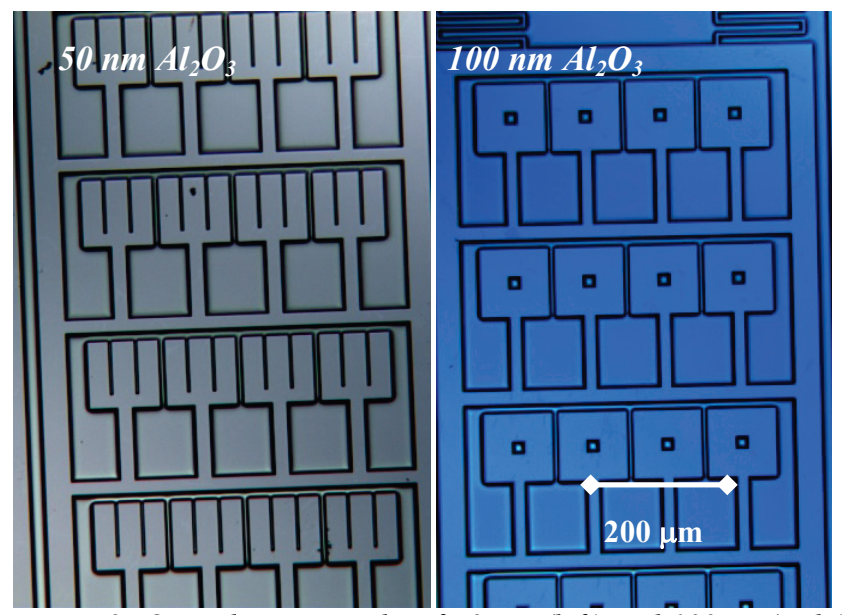

Figure 9: Optical micrographs of $50 \mathrm{~nm}$ (left) and 100 $\mathrm{nm}$ (right), of $\mathrm{ALD}_{\mathrm{Al}} \mathrm{O}_{3}$ on $\mathrm{Si}$ after $50 \mathrm{XeF}_{2}$ etch cycles showing no unintended etching.

Table 1: SOI fabrication process flows using either a) photoresist encasement or b) ALD protective coating to provide etch protection of the Si device layer.
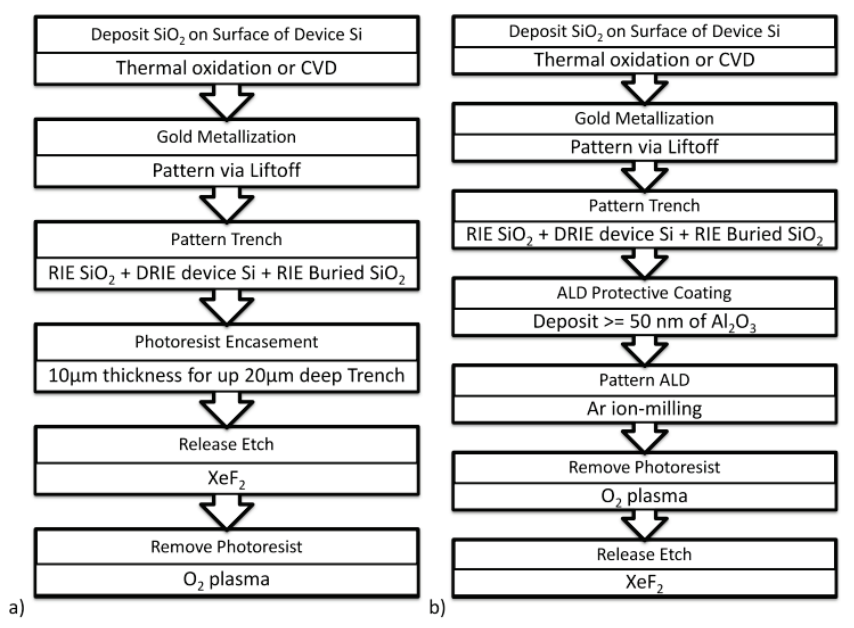


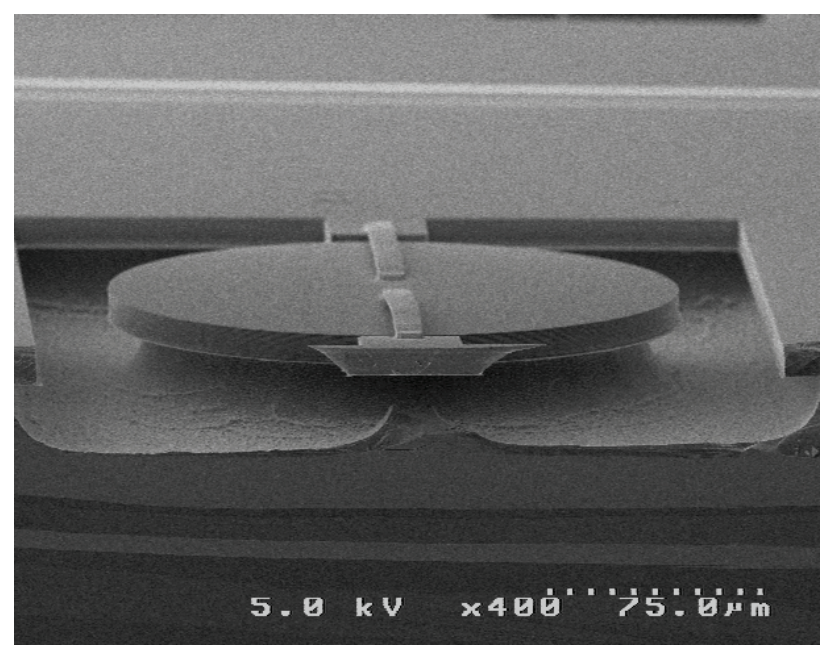

Figure 10: SEM micrograph showing excellent selective protection of Si structure with of $50 \mathrm{~nm}$ of ion milled patterned $\mathrm{Al}_{2} \mathrm{O}_{3}$ film etched in 50 cycles of $\mathrm{XeF}_{2}$. Images were taken prior to full release of devices and after cleaving to illustrate $\mathrm{XeF}_{2}$ etch front. The arrow indicates the isotropic etch.

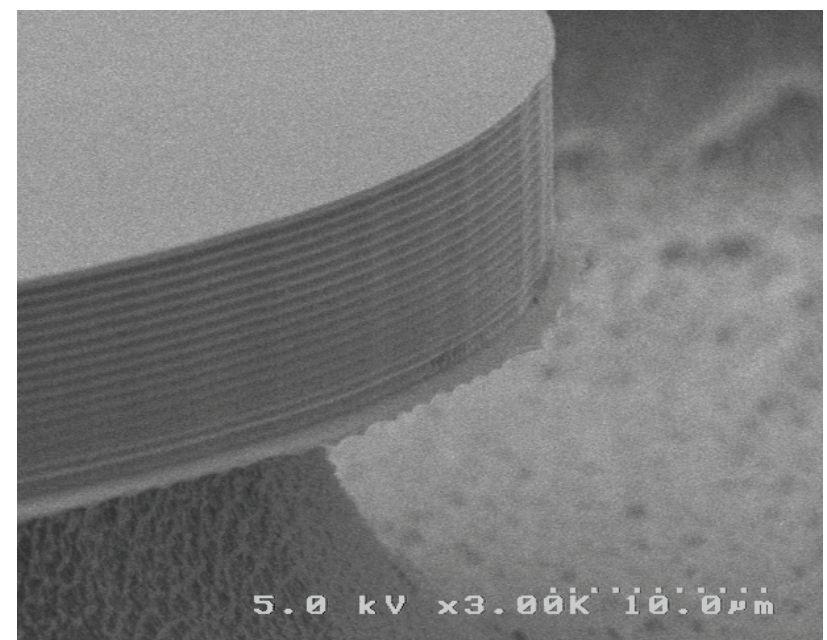

Figure 11: Magnified view of Figure 11. The disk is protected with $A L D$ on the top and sides and $\mathrm{SiO}_{2}$ on the bottom.

\section{CONCLUSIONS}

ALD alumina is a MEMS process compatible, patternable, and etch-resistant mask material to $\mathrm{XeF}_{2}$ etching. Furthermore, it can enable higher performance SOI devices providing improvements in fabrication yield and ease of fabrication integration. Layer thicknesses on the order of 10-50 nm showed good conformal coverage in $15 \mu \mathrm{m}$ deep trench features. Experiments showed that $\mathrm{Al}_{2} \mathrm{O}_{3}$ films greater than or equal to 50 $\mathrm{nm}$ exhibit excellent etch resistance and virtually no pinholing to the $\mathrm{XeF}_{2}$ etch gases for etch cycles ranging from 50 to 500 cycles. Etch failures in films less than $50 \mathrm{~nm}$ thick were clustered, streaked, or at corner features and may be attributed to small contaminates on the wafer or thin areas at sharp convex corner features. It is anticipated that thinner coatings may be successfully utilized but additional research is required to examine the effect of feature size, coating uniformity, and surface contamination.

\section{ACKNOWLEDGEMENTS}

The authors would like to acknowledge Joel Martin, Brian Power and Manrico Mirabelli for their fabrication assistance.

\section{REFERENCES}

[1] N. MacDonald, SCREAM MicroElectroMechanical Systems, Microelectronic Engineering, 32, 1996, 47-73

[2] J. D. Brazzle, M. R. Dokmeci, and C. H. Mastrangelo, "Modeling and characterization of sacrificial polysilicon etching using vapor-phase xenon difluoride," in Proc. 17th IEEE Int. Conf. MEMS, 2004, pp. 737-740.

[3] T. Zhu, P. Argyrakis, E. Mastropaolo, K. Lee and R. Cheung, J. Vac. Sci. Technol. B, 2007, pp. 2553-2557 .

[4] H. Chandrahalim, S.A. Bhave, R. Polcawich, J. Pulskamp, D. Judy, R. Kaul, M. Dubey, Proceedings of 2008 Solid State Sensor-Actuator and Microsystems Workshop, Hilton Head Island, SC, 2008, pp. 360-363.

[5] K. Oldham, J.S. Pulskamp, R.G. Polcawich, M. Dubey, J. MEMS 17, 2008, 890 - 898.

[6] I.W.T. Chan, K.B. Brown, R.P.W. Lawson, A.M. Robinson, Y. Ma and D. Strembicke D, Proc. IEEE Canadian Conf. on Electrical \& Computer Engineering (Edmonton, May 1999), 1999, pp 1637-42.

\section{CONTACT}

*Gabriel Smith, tel: 1-301-394-3722;

gabe.smith@us.army.mil

**Ronald G. Polcawich, tel: 1-301-394-1275;

ronald.g.polcawich@us.army.mil 